\title{
LETRAMENTO, IDENTIDADE E COTIDIANO ENTRE JOVENS XAKRIABÁ'
}

\author{
Carlos Henrique de Souza Gerken* \\ Tamiris Amanda Rezende de Alvarenga** \\ Daniel dos Santos Oliveira*** \\ Ildete Freitas Oliveira****
}

RESUMO: O artigo objetiva descrever os modos de apropriação da escrita e suas consequências nos processos de construção de crenças, valores, capacidades e competências em relação à cultura escrita por jovens indígenas que cursaram o terceiro ano do segundo grau entre 2009 e 2011. A consolidação do projeto de escola diferenciada nas aldeias Xakriabá depende dos mecanismos e das representações por meio dos quais os sujeitos interpretam e dão sentido à escola e às práticas de letramento. Observouse que a escrita no contexto escolar está articulada às demandas sociais e políticas, nas quais jovens escolarizados aparecem como personagens importantes ao lado dos mais velhos, sendo utilizada como mediadora das relações em vários contextos. Além disso, a escrita é importante na construção de narrativas pessoais e coletivas articuladas aos processos de (re)construção da identidade frente às demandas sociais e políticas.

Palavras-chave: Letramento. Cultura escrita. Identidade. Cotidiano.

\footnotetext{
* Doutor em Psicologia da Educação pela Pontifícia Universidade Católica de São Paulo (PUC-Sp) e Professor Associado da Universidade Federal de São João Del Rei (UFSJ). Email: hgerken@superig.com.br

** Mestranda em Psicologia da Universidade Federal de São João Del Rei (UFSJ). Email: tamiris. alvarenga@hotmail.com

*** Graduando do Curso de Psicologia da Universidade Federal de São João Del Rei (UFSJ). Email: busqueser@yahoo.com.br

**** Mestre em Educação pela Universidade Federal de São João Del Rei (UFSJ). Email: ildete. unimontes@gmail.com
} 


\title{
LITERACY, IDENTITY E EVERY DAY LIFE AMONG XAKRIABÁ YOUNGSTERS
}

\begin{abstract}
The article aims to describe the modes of writing appropriation and its consequences to the construction process of beliefs, values, skills and competences related to the written culture of young and indigenous people who concluded the third year of high school between 2009 and 2011. The consolidation of the differentiated-schooling project at Xakriabá villages depends on the mechanisms and representations through which actors interpret and give meaning to school and the practices of literacy. It was observed that the writing in the schooling context is articulated according to social and political demands in which young students appear as important characters along the elders and it is used as a mediating relation in a variety of contexts. Besides that, writing is used in the construction of personal and collective narratives articulated in processes of (res) construction of identity in face of social and political demands.
\end{abstract}

Keywords: Literacy, Writing Culture, Identity, Everyday Life.

Fico vendo o povo que sabe a letra, esse povo aproveita poco, logo num sabe o que ouviu, esquece e não reflete, enquanto eu ouço bem e penso longe... antes meu pai num deixava ir na escola, era longe, muito mato, só trilhos e muito bicho, eu até escondia no mato, daí acho que meus pequenos devem aproveitar mais a escola e saber pensar mais o tempo (D. IAIÁ, Barreiro Preto, 2010).

\section{INTRODUCุ̃̃O}

Desde a criação do Programa de Implantação de Escolas Indígenas de Minas Gerais (PIEI), nos últimos 15 anos, o acesso à escrita ganhou contornos jamais vivenciados pelos Xakriabá. Por essa razão, acreditamos que devemos pensar o letramento em curso nas aldeias Xakriabá como um processo que envolve a elaboração de estratégias culturais, simbólicas, políticas e cognitivas que atravessem e ultrapassem as atividades escolares, que envolvam a construção de concepções e valores que os sujeitos atribuem às suas práticas como parte de uma cultura escrita própria.

Pretende-se, a partir desta investigação, compreender os processos e as condições pelos quais as práticas de letramento constituem as identidades de grupos que vêm vivenciando nos últimos anos processos de escolarização que aumentam o número de sujeitos capazes de usar em seu cotidiano a linguagem escrita. Nosso interesse é descrever os modos ou as estratégias 
de apropriação da escrita e suas consequências nos processos de construção de disposições, crenças, valores, capacidades, habilidades e competências em relação à cultura escrita ${ }^{2}$.

Partimos do pressuposto de que a consolidação do projeto de escola diferenciada em curso nas aldeias Xakriabá só terá êxito se avançarmos na compreensão dos mecanismos de interpretação que estão na base das representações e dos valores por meio dos quais as diferentes categorias de sujeitos Xakriabá interpretam e dão sentido à escola e aos processos de transformação que estão ocorrendo em seu universo sociocultural. Nesse sentido, visualiza-se a importância de estudar de que maneira os alunos, no processo de apropriação da linguagem escrita na escola e fora dela, negociam significados e concepções e atribuem valores ao uso da escrita, mediados pelo seu pertencimento a uma cultura que tem sua identidade básica fundada nos processos de transmissão oral.

Por essa razão, não podemos perder de vista a relação, ao mesmo tempo tensa e cooperativa, que ocorre entre sujeitos mais velhos - responsáveis pela manutenção das tradições, depositários do saber tradicional e de sua lógica de transmissão -, de um lado, e alunos e professores, de outro, que assumem importância decisiva no cenário contemporâneo, não apenas porque representam uma nova categoria de sujeitos letrados, mas porque ocupam o lugar de intérpretes legítimos da cultura Xakriabá, os quais, por intermédio da escola, lutam para que sua identidade seja reconhecida e preservada.

Acreditamos ainda que uma perspectiva metodológica que integre princípios de orientação etnográfica e da psicologia históricocultural seja eficaz para o desvelamento desses processos, uma vez que nos permite articular o estudo de contextos pontuais com um movimento mais amplo da cultura Xakriabá e seus contornos com a sociedade circundante. Assim, a pesquisa com os povos indígenas não pode prescindir de uma discussão teórica que pretenda lançar luz sobre as complexas relações de contato interétnico.

Tassinari (2001) introduz no campo das discussões sobre educação escolar indígena a noção de escolas como "espaços de fronteira". Essa perspectiva desloca o olhar, antes dirigido para o centro das aldeias, para as regiões periféricas ou de intercâmbio, enfatizando as situações de interação entre culturas indígenas e a cultura ocidental.

Por sua vez, Carneiro da Cunha (2009), para discutir os conflitos provocados pelas situações interétnicas, propõe uma distinção entre "Cultura" (com aspas) e Cultura (sem aspas). A distinção básica entre os dois conceitos é que a "Cultura" (com 
aspas) é produzida por meio do contato interétnico; articula tanto os discursos construídos sobre os povos indígenas quanto os discursos e as formas de lidar com o mundo dos brancos pelos próprios povos indígenas. Trata-se de uma lógica que, segundo a autora, é produzida numa relação de conhecimento mútuo e que apresenta uma grande margem de conflitos, sobretudo os que dizem respeito, por exemplo, à propriedade intelectual de bens produzidos nas sociedades indígenas. A "Cultura" (com aspas) é reflexiva e tem a propriedade de uma metalinguagem, sendo resultado do esforço de interpretação de especialistas e pela objetivação dos próprios indígenas ao lidarem com as categorias metropolitanas, com as quais necessitam negociar permanentemente em situações de contato (CARNEIRO DA CUNHA, 2009). É nesse enquadre mais amplo que podemos compreender o processo de letramento que está ocorrendo entre os Xakriabá. É preciso ter em mente que a cultura que se busca investigar está em permanente processo de transformação.

\section{LETRAMENTO, IDENTIDADE E COTIDIANO}

Um dos maiores problemas contemporâneos para as pesquisas em educação é a compreensão das formas pelas quais os sujeitos se apropriam socialmente da linguagem escrita. Muitos esforços educacionais e acadêmicos foram realizados com esse objetivo. $\mathrm{Na}$ tentativa de compreender esse problema, existem diferentes perspectivas teóricas. Recentemente, uma proposta de Brian Street (1984, 1995, 2003, 2007), denominada New Literacy Studies (NLS) - Novos Estudos sobre o Letramento -, surgiu como uma alternativa às concepções dominantes nesse campo, em que aparecem os trabalhos de Goody $(1968,1977)$ e Goody e Watt (2006) entre os mais conhecidos. Para Goody e Watt (2006), oletramentotem comoumade suas consequências o desenvolvimento cognitivo, social e cultural. Desse modo, "o sucesso na manipulação das ferramentas de ler e escrever é, obviamente, um dos eixos mais importantes de diferenciação social em sociedades modernas" (GOODY; WATT, 2006, p. 62).

$\mathrm{Na}$ introdução de sua obra Literacy in theory and practice, Street (1984) sintetiza as razões que o levaram a reavaliar os modelos de análise vigentes no campo do letramento. Sua principal crítica a esses modelos é que o letramento não pode ser pensado como uma prática neutra, autônoma e universal, que resulta na estratificação das sociedades em categorias de sujeitos letrados e iletrados, 
criando-se a ideia de uma "grande divisão". Em sua proposta alternativa, o autor defende que o letramento é resultado de um conjunto de práticas sociais ideológica e politicamente contextualizadas. Por essa razão, não existe letramento no singular, mas letramentos, que se referem a diferentes formas de utilização da escrita, que só podem ser compreendidas a partir dos significados reais atribuídos por diferentes grupos sociais.

Street (1984) afirma a impossibilidade de se analisar a linguagem independente de seu contexto de realização, chamando a atenção para o necessário redimensionamento do conceito de "contexto". Afinal, diferentes sociedades e seus subgrupos sociais possuem diferentes tipos de letramento, e suas práticas estão inteiramente ligadas às identidades das pessoas que as realizam, o que implica, em termos mais profundos, mudanças de identidade mediante a mudança de práticas de letramento.

Street (2007) argumenta que, quando uma pessoa se envolve num quadro institucional de práticas de letramento, seja por meio do trabalho, das relações sociais ou do ativismo político etc., mais do que simplesmente decodificar um texto escrito, produzir ensaios ou escrever, está assumindo ou recusando identidades. Desse modo, as práticas de letramento posicionam o sujeito na sociedade e servem de lugar de negociação e transformação das posições que aparentemente lhe são atribuídas.

Segundo Street (2007), os significados e os usos do letramento em diferentes sociedades são semelhantes aos significados e aos usos da noção de pessoa, na medida em que ambos representam "o que Kirkpatrick chama de campos nos quais as estruturas dominantes e as estruturas ideológicas são visíveis" (KIRKPATRICK, 1983, p. 12 citado por STREET, 2007, p. 469). O autor menciona ainda o trabalho antropológico de Besnier (1991), um estudo específico sobre letramento e noção de pessoa realizado no atol de Nukulaelae, no Pacífico, em que aponta que nessa comunidade:

\footnotetext{
o letramento mesmo é visto como um elemento importante na própria definição de pessoa, na medida em que ser capaz de ler e escrever é pressuposto na caracterização de uma pessoa socialmente competente. O letramento, portanto, está constitutivamente relacionado com a pessoalidade (BESNIER, 1991, citado por STREET, 2007, p. 469).
}

Entre os Nukulaelae, existem dois letramentos que envolvem diferentes aspectos da pessoalidade/identidade: um associado aos sermões e outro associado à redação de cartas. Nos sermões, as práticas de letramento trazem à tona a autoridade, a assertividade, enfatizando 
assimetrias de poder entre o escritor-pregador e a audiência. Por sua vez, as cartas pessoais situam o sujeito num sistema de sociabilidade e preocupação para com os parentes mais jovens (STREET, 2007).

$\mathrm{Na}$ mesma direção, pode-se afirmar que, entre os Xakriabá, existem diferentes formas de letramento, nas quais podem ser observadas múltiplas formas de relação entre a oralidade e a escrita, sendo que a primeira permanece como referência dominante. Observa-se, por exemplo, que leitores proficientes funcionam como mediadores de textos escritos para que sejam interpretados por outros sujeitos que, apesar de não dominarem a escrita, possuem autoridade simbólica para fazer circular sentidos e construir novas interpretações de documentos, da bíblia, das cartas, de informações que chegam pelas agências do Estado etc. Esse jogo de alternância e articulação resulta em formas próprias de construção, compartilhamento e transmissão de significados, que refletem diferentes posições e identidades grupais.

A pesquisa partiu de um conjunto de conceitos que são fundamentais para a compreensão dos letramentos existentes entre os Xakriabá, que vamos expor em seguida.

\section{OS CONCEITOS DE EVENTOS E PRÁTICAS DE LETRAMENTO}

As pesquisas que se enquadram nos Novos Estudos sobre o Letramento ocorrem tradicionalmente com orientação etnográfica tendo centralidade nos conceitos de eventos e práticas de letramento. Para descrever as práticas letradas, Heath (1982), inspirando-se no conceito de evento de fala, utilizado pelo sociolinguista Hymes (1972), desenvolve o conceito de evento de letramento. Para Heath (1982):

O evento de letramento é uma ferramenta conceitual utilizada para examinar, dentro de comunidades específicas da sociedade moderna, as formas e as funções das tradições orais e letradas e as relações coexistentes entre as linguagens falada e escrita. Um evento de letramento é qualquer situação em que um suporte tornase parte integrante de uma interação entre participantes e dos seus processos interpretativos. (HEATH, 1982, p. 93)

A análise de um evento de letramento (por exemplo, aulas, conferências e seminários) se dá por meio da descrição e do questionamento sobre os usos e os significados atribuídos pelos sujeitos aos materiais escritos. Quais são os valores e as concepções acerca do uso e do não uso de suportes para textos escritos como quadro-negro, álbuns seriados, livros didáticos, data-show? Qual agência disponibiliza tais materiais? Em que contexto e com 
quais motivações políticas e institucionais os sujeitos são mobilizados a interagir entre si? Quais relações que os sujeitos estabelecem com as informações transmitidas e com os seus conhecimentos prévios? Como se dão os registros das informações?

Os eventos de letramento são, enfim, comportamentos observáveis de sujeitos em interação que estão imbricados de significado e estruturados em torno de uma gama de mediações sociais, seja por comporem as interações, seja por elucidarem os referenciais culturais dos sujeitos. Por outro lado, a prática de letramento refere-se a uma construção analítica em torno de um determinado conjunto de eventos de letramento que compõem uma dada interação, articulando as mediações sociais que compõem o contexto sócio-histórico e político da interação estudada.

$\mathrm{Na}$ mesma direção, Kalman (2004) estabelece uma distinção entre o que chama de disponibilidade e acesso às práticas letradas. O conceito disponibilidade denota a presença física dos materiais impressos, bem como sua infraestrutura de distribuição (bibliotecas, pontos de venda de livros, revistas, jornais, serviços postais etc.). Já o conceito de acesso se refere às oportunidades concretas de participar de situações em que os sujeitos se colocam frente a frente com outros leitores e escritores, além das oportunidades e das modalidades para aprender a ler e escrever.

$\mathrm{O}$ conceito de acesso às práticas letradas nos permite identificar como se dá a interação entre os participantes dos eventos comunicativos, quais são os desdobramentos de seus conhecimentos, concepções, bem como quais são os sentidos das práticas de leitura e escrita adotadas pelos sujeitos. As relações estabelecidas entre leitores e escritores com os textos, bem como as consequências dos usos estabelecidos, são aspectos fundamentais para pensar as vias de acesso. Outra preocupação é compreender as diversas modalidades de apropriação da leitura e da escrita: Como os grupos constroem os aspectos específicos - conteúdos, formas e convenções - de suas práticas de língua escrita? Quais são os processos de significação e os procedimentos de uso estabelecidos pelos sujeitos? (KALMAN, 2004). A autora estabelece, ainda, o conceito de "espaço gerador", que articula um conjunto de práticas realizadas em resposta a demandas concretas que conferem diferentes sentidos para o uso da escrita.

Galvão (2007) frisa a explicitação do papel ativo dos sujeitos e dos grupos sociais nos processos de letramento afirmando que há uma clara preferência por expressões como "participar da", "relacionar-se com" em detrimento de expressões como "inserir-se na", "entrar na" ou "ter acesso à (às)" cultura(s) escrita(s), uma vez que 
os indivíduos, ao mesmo tempo em que participam de certas culturas do escrito de uma dada sociedade, também são produtores ativos de outras formas - muitas vezes novas - de se relacionar com a leitura e a escrita, que passam a caracterizar também a cultura escrita daquela sociedade (GALVÃO, 2007, p. 39).

Bartlett e Holland (2002) concebem o conceito de "espaço de práticas de letramento" a partir de uma articulação entre o conceito de "prática" de Bourdieu (1983) e a perspectiva histórico-cultural de Bakhtin, Vigotski e Leontiev. Segundo as autoras, essa articulação permite enriquecer o conceito de "práticas de letramento", que é central para o campo dos estudos sobre letramento. A articulação teórica entre a antropologia cultural (HEATH, 1982; STREET, 1984), a psicologia cultural (SCRIBNER; COLE, 1981) e a sociolinguística aplicada (GEE, 1990; BARTON; HAMILTON, 1998; BARTON, 1994; BAYNHAM, 1995) visa superar a perspectiva universalizante a partir da qual o fenômeno do letramento foi tratado nas décadas de 1960 e 1970. Tal especificidade conceitual compõe o sentido etnográfico que a produção desse campo apresenta com os conceitos de "práticas de letramento" e "eventos de letramento", contemplando-se os usos sociais da leitura e da escrita.

O conceito de "apropriação" completa o referencial conceitual proposto por Kalman (2004) e se refere ao momento efetivo em que sujeito e textos escritos se encontram. Isso significa dar sentidos múltiplos ao uso do material escrito, incluindo as várias e diferentes interpretações e, consequentemente, as múltiplas compreensões do lido, o que nos permite perceber a forma particular com que os sujeitos interagem com a leitura e a escrita.

Tomando como referência esses conceitos, o objetivo do trabalho é compreender as práticas sociais de uso da linguagem escrita por parte de jovens que concluíram o $3^{\circ}$ ano do Ensino Médio nos anos de 2010 e 2011, na escola Xukurank, situada na Aldeia Barreiro Preto. As perguntas que orientaram a pesquisa podem ser definidas nos seguintes termos: quais os lugares que a leitura e a escrita ocupam na vida cotidiana dos sujeitos Xakriabá que concluíram o $3^{\circ}$ ano do Ensino Médio? Quais são os determinantes sociais, históricos, políticos, econômicos e culturais que estruturam tais momentos cotidianos de modo que possamos tratá-los como práticas de letramento? Quais as concepções, os valores e as expectativas que esses sujeitos apresentam acerca de suas práticas de leitura e escrita?

No próximo item, faremos uma breve descrição da metodologia e do contexto da pesquisa. 


\section{OLHAR, OUVIR E ESCREVER}

A preparação para o trabalho de campo na perspectiva etnográfica consiste em uma reeducação do olhar e da intuição por meio de discussões teóricas. Busca-se a abertura para elementos específicos da cultura do outro, a partir da conscientização e do questionamento da nossa própria cultura, bem como do olhar que esta nos condiciona a lançar sobre o outro.

Oliveira (1998) sintetiza a perspectiva antropológica em três palavras-chave: olhar, ouvir e escrever. O que diferencia esses atos cognitivos no fazer antropológico é justamente o trabalho de domesticação reflexiva que o pesquisador faz de sua percepção e de sua intuição, de forma que estas se mostrem capazes de reconhecer, nos detalhes imperceptíveis ao olhar destreinado, as mediações sociais que compõem o objeto de estudo. Nesse sentido, buscou-se nas jornadas de campo fazer a descrição de como os eventos e as práticas de letramento estão inseridos no cotidiano da Aldeia Barreiro Preto da Terra Indígena Xakriabá, refletindo sobre como os diferentes sujeitos indígenas participam das diferentes atividades cotidianas e quais os processos de socialização privilegiados.

Os dados foram coletados na Aldeia Barreiro Preto em três jornadas de campo, totalizando 30 dias aproximadamente, entre o período de fevereiro de 2010 a junho de 2011, por meio de observações participantes, registros audiovisuais das práticas e dos eventos investigados, além de entrevistas abertas, feitas individual e coletivamente, registradas em áudio e/ou diários de campo. Utilizou-se a observação participante do contexto escolar, familiar e comunitário; foram realizadas entrevistas abertas com alunos, professores, lideranças e membros da Aldeia Barreiro Preto, cujas narrativas foram tomadas como forma privilegiada de acesso às significações construídas.

Um último elemento de nossa atuação foi verificar as expectativas dos jovens a respeito da aquisição da escrita, constituindo informações para a sistematização dos valores e das concepções por eles construídos em torno das práticas de letramento. Tal momento é o que aponta mais diretamente para a situação de entrevista, que, por sua vez, é um elemento tão constituinte do fazer etnográfico quanto a observação.

Os dados desta pesquisa foram produzidos e analisados a partir do contato com os alunos do terceiro ano do Ensino Médio da escola Xukurank entre 2009 e 2011. Todavia, antes da discussão dos 
dados, faremos uma breve descrição dos Xakriabá, especialmente da Aldeia Barreiro Preto e da escola Xukurank, onde foram realizadas nossas observações e entrevistas.

\subsection{CONTEXTUALIZAC̣ÃO DOS XAKRIABÁ, DA ALDEIA BARREIRO PRETO E DA ESCOLA XUKURANK}

Localizados no Norte de Minas, junto aos municípios de Itacarambi e São João das Missões, os Xakriabá apresentam, segundo o Conselho dos Povos Indígenas de Minas Gerais - COPIMG ${ }^{3}$ (2009), uma população de aproximadamente 8.000 habitantes. De acordo com a Fundação Nacional do Índio - FUNAI (2010), formam um dos grupos indígenas mais numerosos do Brasil e são distribuídos em 34 aldeias e subaldeias, localizadas em extensões de terra demarcadas pelo governo federal denominadas Terra Indígena Xakriabá (46.470 hectares) e Terra Indígena Xakriabá Rancharia (6.500 hectares).

Do ponto de vista de sua história e constituição enquanto grupo indígena, os Xakriabá pertencem ao conjunto étnico dos chamados "índios do nordeste", que são povos distintos que se adaptaram à Caatinga e historicamente estão ligados às frentes pastoris e ao padrão missionário dos séculos XVII e XVIII (DANTAS, et al., 1992). Constituíram-se a partir da missão católica de São João dos Índios, originada entre os séculos XVII e XVIII, abrangendo índios de várias etnias localizadas na região do alto São Francisco. Ao longo da década de 1970, quando os movimentos organizados por campesinos passaram a ganhar destaque no Brasil, iniciou-se um processo de reconhecimento da identidade étnica dos Xakriabá.

A economia local é baseada em diversas atividades, principalmente a agricultura familiar e a pecuária de subsistência. No entanto, em função do aumento do período de estiagem e da queda da produção agropecuária, jovens e adultos migram temporariamente para São Paulo e Mato Grosso para trabalharem em lavouras de cana. $\mathrm{O}$ acesso a programas governamentais de assistência social, como o "Bolsa Família", tem sido fundamental para a sobrevivência de famílias que não conseguem reproduzir sua força de trabalho.

Na década de 1990, os Xakriabá vivenciaram um conjunto de transformações econômicas, culturais, políticas e sociais. Do ponto de vista econômico, a universalização do acesso à escola por meio do Estado (Secretaria de Estado de Educação de Minas Gerais SEE/MG), o acesso às políticas públicas no campo da saúde, como saneamento básico (Fundação Nacional de Saúde - FUNASA), 
infraestrutura (instalação da rede elétrica - CEMIG), e as políticas de distribuição de renda (Ministério do Desenvolvimento Social e Combate à Fome - MDS) implicaram o surgimento de diferentes profissões assalariadas (professores indígenas, auxiliares da escola, agentes de saúde) e o aumento da renda da população. Esse novo cenário permitiu o acesso a novos bens de consumo, como carros, motocicletas, aparelhos de som, celulares e computadores.

Com uma maior conscientização e mobilização na luta pela garantia de seus direitos, os Xakriabá ampliaram a sua participação na vida política do município de São João das Missões, o que resultou na eleição de representantes da etnia para a Câmara Municipal e do primeiro prefeito indígena do Estado de Minas Gerais, em 2004.

Devido à extensão territorial da área indígena Xakriabá e à riqueza e à diversidade culturais existentes em suas várias aldeias, foi necessário definir um lócus privilegiado para a realização da pesquisa, a fim de compatibilizar o tempo e os recursos disponíveis. Assim, foi feito um recorte de acordo com os contatos anteriormente estabelecidos pela equipe, segundo a facilidade de acesso geográfico por meio de estradas de terra onde é possível o trânsito de veículos motorizados. Optou-se por investigar os jovens que finalizavam o terceiro ano do Ensino Médio na escola Xukurank, da Aldeia Barreiro Preto, entre os anos de 2009 e 2011.

\subsubsection{Aldeia Barreiro Preto}

O Barreiro Preto é um foco privilegiado de pesquisa em virtude de três outros fatores: em primeiro lugar, representa um importante centro populacional da reserva Xakriabá. Em segundo, é nessa aldeia que se localiza a escola Xukurank, núcleo escolar que oferece todas as séries do Ensino Fundamental e do Ensino Médio. Em terceiro, apresenta uma história de escolarização anterior à criação do Programa de Implantação das Escolas Indígenas de Minas Gerais (PIEI/MG), característica fundamental para a compreensão tanto da prática educacional dos professores quanto dos processos de apropriação da linguagem escrita por parte dos alunos.

A aldeia está localizada na área central da Terra Indígena Xakriabá, não estabelecendo fronteiras com cidades vizinhas. A relevância de sua posição geográfica com respeito à reafirmação da identidade étnica é enfatizada no discurso de um dos seus líderes, senhor Vicente ${ }^{4}$ " "a nossa aldeia não faz divisa com os brancos".

Possui aproximadamente 800 habitantes, representando o terceiro maior contingente populacional da terra indígena (apenas as 
aldeias de Sumaré e Brejo do Mata Fome possuem um número maior de habitantes). Seu povoamento foi influenciado pela presença de nascentes de água, as quais, em sua maioria, já secaram. Hoje resta apenas uma nascente, conhecida como Olhos d'Água. A existência dessa nascente foi um dos fatores responsáveis pela migração de moradores de outras aldeias para a região. A lógica de ocupação das terras baseia-se nas relações de parentesco. Dentro de um mesmo terreno, duas ou três casas formam pequenos núcleos familiares, que se distribuem ao longo dos caminhos que atravessam a aldeia.

\subsubsection{A escola Xukurank: espaço de vida e saber}

A escolarização na Aldeia Barreiro Preto se iniciou em 1970, com uma escola municipal administrada pela Prefeitura de Itacarambi, que a nomeou como Escola Frei Caneca. Antes desse período, as famílias que dispunham de melhores condições eventualmente contratavam professores de fora para ensinar a ler e escrever. Em outros casos, membros da comunidade que dominavam a escrita assumiam essa tarefa de ensinar a ler e escrever.

A Escola Estadual Indígena Xukurank foi fundada em 1997, após a introdução do PIEI. Atualmente, oferece Educação Infantil, Ensino Fundamental e Ensino Médio ${ }^{5}$. Seu corpo docente é formado por professores indígenas eleitos pela própria comunidade. Sua nova sede foi inaugurada em dezembro de 2002, obedecendo a uma arquitetura que privilegia o arejamento dos ambientes e proporciona visão ampliada do espaço externo (ver Foto 1). Possui quatro prédios, construídos com base em desenhos que foram feitos por professores e alunos e trabalhados por arquitetos do Estado, para proporcionar diferentes espaços de convivência, todos eles, adequados ao clima quente do local, com paredes vazadas, construídas com vigas de madeira e tijolo.

O primeiro prédio é destinado ao setor administrativo (diretoria e secretaria) e salas de aula; o segundo, para biblioteca e sala de aula; o terceiro, apenas para sala de aula; e o quarto, para banheiros e cozinha. Vale lembrar que, no pátio da escola, existem ainda duas construções: um centro comunitário, utilizado para reuniões de caráter político e religioso, e a Casa da Medicina, onde se desenvolve um projeto de tratamento de ervas tradicionais e o aprendizado e o cultivo de novas ervas que podem ser utilizadas no tratamento de várias doenças.

Sua biblioteca conta com um acervo de livros diversificado, contendo obras literárias, livros didáticos, revistas e enciclopédias 
para pesquisa, além de livros que narram a história Xakriabá. Possui também um computador com acesso à internet, que é usado não apenas para a realização de pesquisas pelos alunos, mas também como instrumento de acesso às redes sociais, por meio das quais ampliam o contato com a vida fora da aldeia. Sem dúvida alguma, a construção dos novos prédios escolares redimensionou as possibilidades do trabalho pedagógico no interior da instituição escolar.

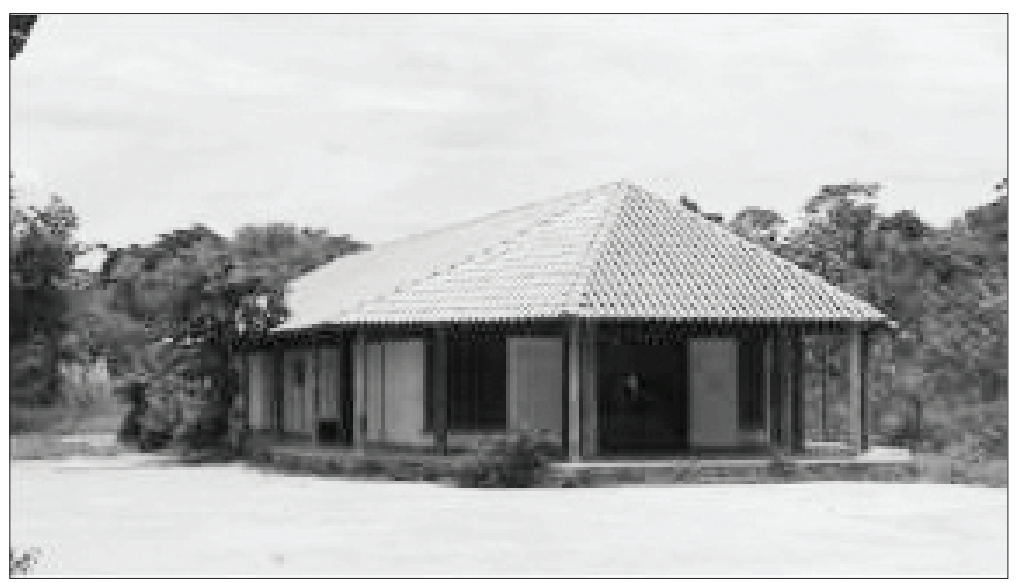

FOTO 1 - Vista parcial da escola Xukurank na Aldeia Barreiro Preto (06/2011). Imagem de um dos prédios de salas de aula.

A construção de uma escola indígena diferenciada, que é o principal objetivo pedagógico assumido pelos professores, implica uma preocupação permanente de articulação entre os saberes produzidos e transmitidos pela escrita e os conhecimentos tradicionais transmitidos oralmente. As disciplinas do núcleo comum ministradas no segundo grau (língua portuguesa, matemática, ciências da natureza, geografia, história, filosofia e arte) são articuladas a um núcleo diferenciado de disciplinas (Uso do Território, Cultura Xakriabá e Práticas Culturais).

Os livros didáticos utilizados nas disciplinas da Base Nacional Comum são fornecidos pela Secretaria de Estado da Educação de Minas Gerais (SEE - MG). Curioso observar que, apesar da ampla disponibilidade de materiais didáticos aos professores, na maioria das vezes, eles preferem utilizar para a preparação de suas aulas os materiais didáticos construídos nos cursos de formação.

Dentre esses materiais, existem publicações produzidas pelos professores que tratam da história e da cultura Xakriabá, como o livro Com os Mais Velhos (2005), que acompanha um CD de áudio; 
o livro Iaiá Cabocla (2005), que contém poesias sobre um dos seus principais mitos de origem; o livro Revelando os Conbecimentos (2005), que contém uma descrição da linguagem cotidiana em comparação à escrita da língua portuguesa padrão; e o livro Sobre a Literatura Xakriabá (2005), da professora Elza Gonçalves da Silveira, que é um estudo acadêmico sobre a cultura e a literatura oral Xakriabá. Além desses materiais, existem outros livros, como O tempo passa e a história fica (1997), que narra a história do conflito que resultou na emancipação dos Xakriabá, além de outros livros produzidos por outras etnias, como os Pataxó, os Krenak e os Maxakali.

Tendo realizado a contextualização da Aldeia Barreiro Preto e da escola Xukurank, apresentaremos em seguida a discussão dos resultados da pesquisa.

\section{LETRAMENTO DE ALUNOS E EX-ALUNOS DO TERCEIRO ANO DA ESCOLA XUKURANK}

A partir da tarefa de verificar como os jovens Xakriabá participam e constroem as práticas de letramento junto à comunidade, bem como de perceber quais são os valores e os sentidos por eles atribuídos ao uso da linguagem escrita, observou-se a existência de vários espaços de práticas de letramento (BARTLET; ROLLAND, 2002), que mostraram uma estreita relação com o processo de reconstrução da identidade indígena desses jovens, a saber: o uso escolar; a participação em redes sociais e o uso da escrita mediado pelo computador e a internet; a casa e o trabalho; e o uso da escrita como forma de preservar a trajetória individual e a memória coletiva.

\subsection{OS USOS DA LINGUAGEM ESCRITA NO CONTEXTO ESCOLAR}

Observou-se que existem muitas formas de utilização da linguagem escrita no contexto escolar. Embora haja predominância da cópia de textos escritos pelos professores no quadro, Arlindo, professor de língua portuguesa do terceiro ano do Ensino Médio, afirma que são realizadas em sala de aula atividades como leituras coletivas e produção de textos por meio de relatórios de atividades realizadas nos projetos da aldeia, de viagens da turma para fora da área indígena e de entrevistas sobre a cultura indígena feitas com as pessoas mais velhas. Nesse ponto, pode-se perceber que os usos escolares da língua escrita acompanham as diferentes dimensões cotidianas que têm sido demandadas aos Xakriabá nos últimos 
anos, que envolvem uma intensificação de sua participação nas atividades do movimento indígena fora das aldeias e nos projetos de sustentabilidade da Terra Indígena Xakriabá.

Observou-se, por exemplo, que a escola solicitou várias vezes aos alunos do Ensino Médio que fizessem relatos dos seminários que ocorreram na aldeia para prestação de contas das atividades da Prefeitura de São João das Missões ${ }^{7}$ e outros encontros para avaliação da questão da educação e da saúde na comunidade indígena. Esses relatos são objetos de trabalho em sala de aula, fazendo-se com que a escrita se transforme num instrumento concreto de apropriação do real social.

Há também a produção de textos sobre as leituras realizadas na escola. O material que subsidia essas atividades é disponibilizado na biblioteca da escola, que conta com um acervo composto, em sua maioria, por livros das coleções do Programa Nacional de Bibliotecas Nacionais (PNBE), recebidos diretamente do governo ou doados por outras bibliotecas. São títulos no campo da literatura nacional e da internacional, dicionários, enciclopédias e outros livros didáticos, que são utilizados como suporte para as atividades de ensino, além dos livros de autoria dos próprios Xakriabá.

Noel, professor de literatura e cultura indígena, fala sobre o acesso à biblioteca e como as atividades em sala de aula são estruturadas:

E: Como é que você trabalha com a biblioteca dentro da escola?

$\mathrm{N}$ : A biblioteca eu, tens uns livros que às vezes tem, que eu dou algum trabalho pra eles, e aí eu falo com eles: "Vocês procuram o livro lá, tal livro de literatura, e aí lê e aí anota numa folha pra mim o nome do livro, o título do texto que leu, o autor, e aí faz um pequeno resumo do texto que leu: o texto contava a história disso e disso, o que aconteceu no meio da história, no final da história”. Aí eles me entregam o papelzinho... Aí eles pegam o livro, lê e depois devolve. Aí tem livro de literatura, tem vários estilos, tem conto, novela, tem poesia, tem aqueles textos grandes. Eles não gostam não, preferem texto menor. E aí é mais ou menos assim (NOEL, 2010).

Apesar de a escola disponibilizar diversos tipos de materiais escritos, o acesso dos alunos a eles é predominantemente voltado para as atividades escolares. Nesses momentos, é preciso construir uma dinâmica própria que corresponda à necessidade e ao ritmo dos alunos. Eliana, aluna do terceiro ano da turma de 2009, relata haver momentos em que a aula se torna cansativa pelo uso constante das atividades de leitura e escrita, momento em que as atividades são interrompidas para serem desenvolvidas outras dinâmicas e brincadeiras para descontração: 
[...] vira uma diversão na sala, torna-se uma diversão, e às vezes a gente vai escrevendo, vai cansando, só lendo, cansando, resolve umas brincadeira de uma hora pra outra, vira uma dinâmica na sala que todo mundo possa participar. Que vai indo, vai indo, dá sono, aí: "Vamos fazer uma brincadeira? Vamos!". Aí brinca todo mundo e continua a aula de novo (ELIANA, 2010).

Outras disciplinas que são trabalhadas na escola Xukurank constituem-se em espaços para discussões promovidas em sala, provocando mediações entre a vida dos alunos e a história cultural Xakriabá. Em uma observação feita no terceiro ano do Ensino Médio, um episódio chamou-nos a atenção. Durante a leitura de um texto que dizia respeito às leis nacionais sobre os direitos indígenas, uma das alunas da turma lembrou-se da luta de seu povo na conquista de suas terras e questionou aos demais colegas se a luta havia acabado, provocando uma discussão política sobre as lutas contemporâneas dos Xakriabá. Prontamente, outros alunos se manifestaram e trouxeram para a discussão episódios vivenciados pelos antigos índios Xakriabá (DIÁRIO DE CAMPO, 2010).

Além dessas atividades que propiciam a articulação entre os eventos e as práticas escolares de letramento e o meio sociocultural, existem outras que estabelecem a mesma função. São elas: a produção de relatórios acerca dos projetos realizados na aldeia, a elaboração de memoriais e a realização de pesquisas na biblioteca por meio dos livros do acervo e pelos computadores que dão acesso à internet. Essas atividades, além de incitarem os alunos a participarem do meio social em que vivem e a elaborarem a própria cultura, possibilitam o acesso ao conhecimento existente na sociedade brasileira em diferentes campos do saber.

Dentre as tarefas citadas, foi possível ter acesso ao memorial construído por uma jovem do terceiro ano do Ensino Médio. Por meio das 26 páginas escritas, a aluna se debruça sobre sua trajetória escolar, os cursos técnicos que fez, sua participação nos projetos comunitários e suas ambições na vida profissional. Em vários momentos no texto, a jovem narra episódios, vivenciados por ela e colegas, que ilustram o encontro entre diferentes sujeitos étnicos e sociais. Sobre isso, Dolores fala: "Eu sou uma pessoa que não viajo muito, mas de vez em quando eu participo de seminários, encontros, protestos, conferências entre outros. Sempre que participo, é algo ligado a terra, água, reflorestamentos, retomadas" (DOLORES, 2010).

Retomando aos dados do memorial de Dolores, a jovem comenta sobre a sua participação na aldeia e sobre algumas de suas expectativas com relação à sua vida acadêmica: 
O curso de formação Jovem Agricultor faz você acreditar mais no seu potencial, mostra que você tem capacidade de adquirir novos conhecimentos e incentiva sobre os nossos direitos [...]. Ele promove reivindicações, e também os professores querem saber se realmente estamos preparados para saber nos defender (DOLORES, 2010).

Eder (2003) afirma que o reconhecimento de um povo é fundamentado em narrativas de vitórias ou derrotas, que definem um mundo comum de significados distinguindo o "nós" dos "outros". Observa-se que esse trabalho de construção identitária por meio do uso da linguagem escrita na escola é de suma importância para a vida desses jovens indígenas. Desse modo, a escola é vista não apenas como espaço de transmissão e aprendizagem do conhecimento legitimado pela sociedade brasileira, mas, sobretudo, um espaço de reelaboração de identidades sociais e políticas.

\subsection{A PARTICIPAC̣ÃO EM REDES SOCIAIS E 0 USO DA ESCRITA MEDIADO PELO COMPUTADOR E A INTERNET}

Outra relação com a escrita que se pôde observar na escola é realizada mediante o uso do computador que a escola possui na sala da diretoria. Esse computador tem acesso via satélite à internet e é usado tanto pelos funcionários da escola quanto pelos alunos e até mesmo pelos demais moradores da aldeia. A sala fica aberta durante todo o expediente da escola, e o computador fica ligado por todo esse tempo. As pessoas têm acesso livre à máquina.

No ano de 2010, instalaram-se novos computadores e pontos de internet na biblioteca. Com isso, os alunos e a comunidade passaram a usá-los preferencialmente nesse ambiente. Eliana (2010b) relata como é sua relação com esse recurso tecnológico:

\footnotetext{
E: Você costuma entrar na internet?

El: Costumo, quase todo dia eu vou lá na internet.

E: E o que você gosta?

El: Pesquisar, fazer pesquisa assim, na maioria das vezes é pesquisa que os professores passam pra gente, eu vou lá pesquisar, imprimo. Às vezes escrever alguma coisa assim digitado, né? (ELIANA, 2010).
}

Os sites de relacionamento utilizados por esses sujeitos possuem um espaço denominado "perfil", onde os usuários fornecem informações pessoais, preferências, enfim, mostram quem são. Os perfis dos alunos Xakriabá nesses sites são usados como espaços de ressignificação da identidade indígena com o uso da língua Xakriabá, que está sendo reinventada por meio de pesquisas realizadas pelos 
moradores mais velhos e pelos alunos. Os alunos também expõem fotos de atividades indígenas, como danças e festas, durante as quais fazem uso de vestimentas e pinturas tradicionais. Afirmam que aprendem a trabalhar com o computador por meio do contato com pessoas da própria aldeia que já dominam esse instrumento.

Nesse processo de apropriação de uma nova tecnologia, ocorre uma articulação muito interessante entre o uso da escrita e a comunicação oral. Observa-se que existe a intenção de reproduzir diferentes dimensões da tradição da aldeia por meio da escrita. A oralidade está em constante contato com a língua escrita, o que produz práticas de letramento próprias dos Xakriabá, em que a escola se converte em lugar importante de reflexão sobre a linguagem escrita. Por meio dessas práticas, os alunos se comunicam com pessoas de vários lugares, índios e não índios, trocando mensagens e significados socioculturais.

Assim, as redes contemporâneas de comunicação tornam-se exemplos de quebra de fronteiras sociais e étnicas em que, por um lado, ocorre uma intensa interação entre os sujeitos, mas, por outro, há também a preservação da identidade (BARTH, 1998). Isso pode ser evidenciado no modo como os jovens Xakriabá constroem seus perfis nas redes, usando os nomes com significados em sua língua indígena em vez do sobrenome de família, por exemplo. Wahã kn, que significa "eu sou assim", e ciprede kurinã, que significa "grande índio", são expressões na língua Akwê usadas por um jovem Xakriabá para se identificar no seu perfil em uma rede social . Essas práticas representam um movimento dialético no qual se podem observar, de um lado, modificações de seus sistemas de representação ao serem introduzidos em novos espaços de trocas simbólicas e, de outro lado, a afirmação de sua própria identidade por meio da construção de novos signos e da reinvenção das formas de autoidentificação e de trocas entre os pares.

\subsection{OS USOS DA LINGUAGEM ESCRITA NA CASA E NO TRABALHO}

O contexto cultural das aldeias está sendo profundamente modificado em função da presença da linguagem escrita. Há poucos anos, podia-se afirmar que, em sua maioria, os alunos que atuavam no campo e/ou que se dedicavam a trabalhos domésticos não eram demandados cotidianamente ao uso da linguagem escrita. Atualmente, não podemos fazer essa afirmação. No campo, por exemplo, o plantio de sementes distribuídas pelas agências de promoção do 
desenvolvimento da agricultura obriga jovens e adultos a criarem estratégias de leitura para ler as instruções de plantio em envelopes e latas, que explicam os cuidados para a preservação das sementes.

Outro exemplo pode ser observado na área de saneamento básico, em que trabalhadores indígenas usam cada vez mais a linguagem escrita para levar à população informações acerca de como o sistema é realizado e como proceder para prevenção de doenças. A seguir, uma foto tirada de uma apresentação à comunidade realizada por um agente indígena de saneamento.

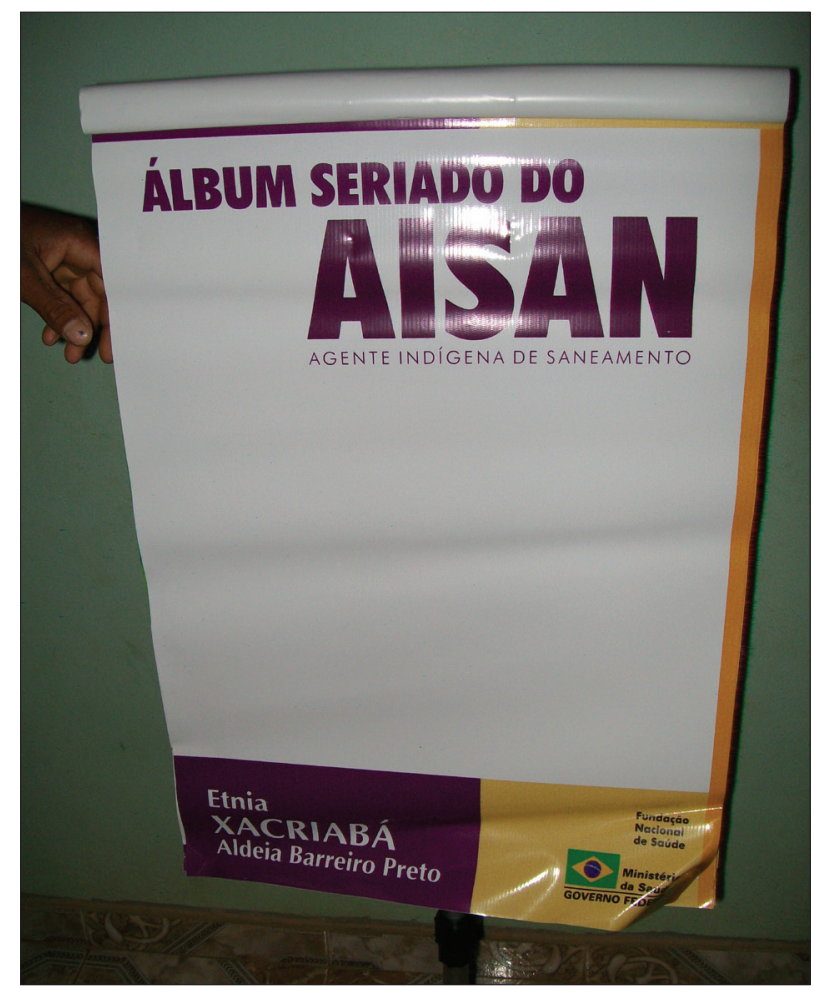

FОTO $2^{9}$ - Apresentação à comunidade realizada pelos próprios agentes indígenas.

O espaço familiar possui uma dinâmica que demanda o uso da linguagem escrita. Nas casas que visitamos, pudemos observar particularidades que são decorrentes de necessidades específicas colocadas pela história e a situação pessoal de cada aluno, bem como das suas formas de inserção no contexto da comunidade. As casas são repletas de materiais escritos, desenhos e cartazes colocados nas paredes. As mesas da cozinha e/ou da sala são cobertas com plásticos transparentes sob os quais são depositados (e, por vezes, 
permanecem por longo período de tempo ${ }^{10}$ ) materiais escritos que vão desde poemas, avisos de reuniões, listas de compras, números de telefones de pessoas importantes para o relacionamento familiar até desenhos de crianças e outras formas de registro escrito do cotidiano.

Observa-se, desse modo, que a mediação da escrita já faz parte do cenário cultural Xakriabá. Em poucas casas, observou-se a presença de livros que são lidos pelos alunos. Existe disponibilidade de um conjunto de textos que os próprios Xakriabá produziram sobre a sua história recente de lutas pela conquista da terra, além de outros textos nos quais há narrativas dos mais velhos. Esses textos, que são lidos e relidos na escola e fora dela, se tornaram emblemáticos por sinalizarem o momento em que a escrita passou a ser um novo instrumento de reflexão e registro da própria história da aldeia. Esses materiais constituem o acervo dos primeiros textos do que pode ser chamado de uma literatura Xakriabá.

Nas visitas às casas dos moradores da aldeia Barreiro Preto, como dissemos, percebemos muitos textos e frases escritos ou colocados em lugares onde qualquer pessoa que chegue ao local possa vê-los. Na casa de João, aluno recém-formado no Ensino Médio, observaram-se, nas paredes e em objetos dispostos sobre os móveis, inscrições com trechos da bíblia, nomes dos integrantes da família, seu certificado de conclusão de curso do Ensino Médio, enfim, vários tipos de textos compondo a decoração da casa. A seguir, duas fotos que ilustram esse cenário.

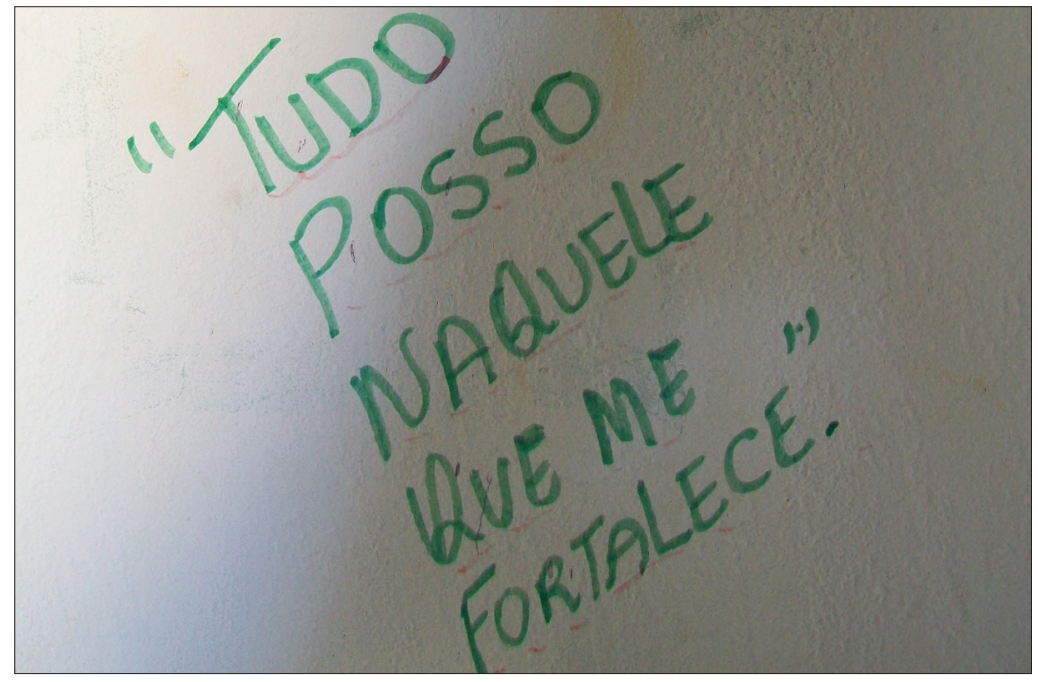

FOTO $3^{11}$ - Trecho da Bíblia escrito na parede da casa de João (06/2011). 


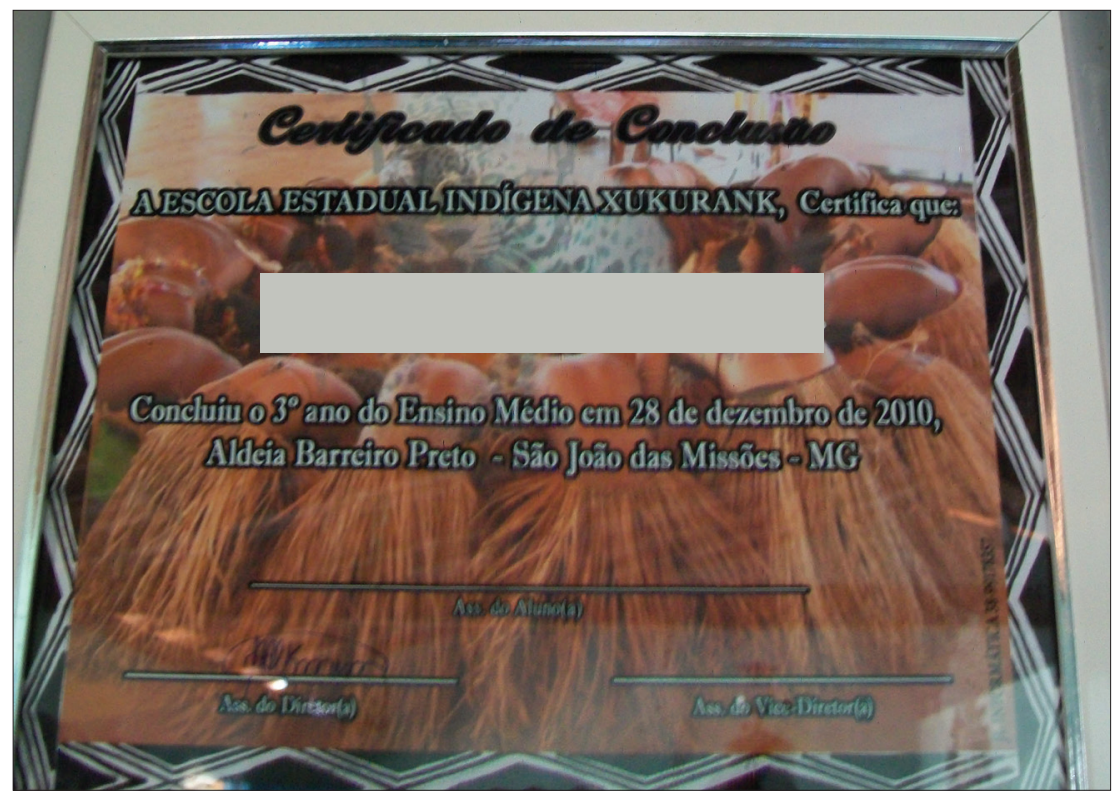

FOTO 4 - Casa do João - Certificado de Conclusão do Ensino Médio da escola Xukurank ${ }^{12}$ (06/2011).

Ao perguntarmos os motivos pelos quais aquelas frases e quadros estavam nas paredes, João respondeu: "O quadro (certificado) é porque é um orgulho pra mim mostrar pra todo mundo que agora eu já estou formado, né? [...] As palavras da bíblia são para proteger a casa, e os outros é pra enfeitar mesmo" (JOÃO, 2011).

A questão do orgulho foi salientada diversas vezes durante as entrevistas e em outras oportunidades. Para esse jovem, a apropriação da linguagem escrita, agora representada pelo quadro na parede, além de significar a conquista de autonomia nas relações de trabalho e em outras situações cotidianas em que a escrita é demandada, pode ser relacionada com o que Street (2007) denomina de "pessoalidade", uma vez que a exposição nas paredes da linguagem escrita representa a mudança de seu lugar social e a expectativa de reconhecimento pelo outro dessas novas possibilidades de trocas simbólicas. Sobre isso o jovem comenta:

Quando eu quase não sabia escrever e lia pouco também eu sentia muita dificuldade no trabalho [...] Eu não sabia preencher as fichas, desenvolver o trabalho e passar pras pessoas que trabalham com a gente, que é o povo da gente [...]. Hoje não. Eu dou uma lida ali e consigo realizar mais fácil aquele trabalho que eu achava difícil. Até mesmo os colegas meus que trabalham, que têm pouco estudo, eles pedem pra gente dar uma força pra eles, ajudar a preencher as fichas [...] Aí a gente pode dar essa força também pra ajudar (JOÃO, 2010). 


\subsection{USO DA LINGUAGEM ESCRITA COMO INSTRUMENTO DE RECUPERAÇ̃̃O E PRESERVACְ̃̃O DE MEMÓRIAS}

Existem, ainda, momentos em que se faz o uso da linguagem escrita como um meio de promover o resgate e a manutenção da memória da trajetória pessoal e de fatos que marcam a história e a cultura Xakriabá. Um evento que pode ser observado entre os jovens é a construção de diários pessoais que carregam traços do grupo como um todo. Sobre isso, Dolores (2011) nos revela:

Gosto de escrever e gosto de ler. Escrevo sobre a minha vida, sobre o que estudo. Tenho um diário que é igual ao memorial. É o registro das coisas que aconteceram comigo. A gente nunca esquece, mas é bom guardar. Aprendi com as minhas irmãs mais velhas. Pode servir até mesmo com os filhos... o que o pai contava da época das lutas da terra da reserva. É mais pra deixar para os filhos [...] (DOLORES, 2011).

Esse trecho corrobora a ideia de que a linguagem escrita por vezes aparece como um momento de fruição, de prazer e, ao mesmo tempo, como instrumento de reconstrução da trajetória pessoal. Por meio da escrita, são registradas passagens que merecem ser preservadas para serem transmitidas às futuras gerações. Servem, outrossim, como registro das memórias coletivas do grupo. Representam um tipo de letramento que, segundo Street (2007), além de inserir o sujeito num sistema de sociabilidade, demonstra a preocupação deste para com seus parentes mais jovens. Essa maneira de utilizar a linguagem escrita é explicitada por Sônia (2010), jovem já formada no Ensino Médio, da seguinte forma:

Eu acredito assim, mesmo aliando a escrita com os nossos contos, com as nossas histórias e conversas, eu acho que essa foi a oportunidade de registrar aquilo que nós já tínhamos, né? Em valores de fala, de povo mesmo, de pessoas. Até porque nossos mais velhos, a maioria não teve essa oportunidade da escrita, né [...]. Quando a gente fala em colocar em escritas as coisas que os mais velhos nos contavam, nos contam, eu acho que esse é o momento de reviver o nosso passado, para ter um melhor presente e tentar um melhor futuro. Então, é com muito prazer que a gente faz esses registros, porque é o momento de valorização do nosso povo e de deixar escrito na história a nossa luta (SÔNIA, 2010).

Além disso, essa modalidade de uso da escrita nos remete ao que Santos (1997) afirma sobre a importância da reconstrução, no plano imaginário, da experiência vivida no contato com o outro, na elaboração da identidade étnica. O uso da linguagem escrita representa uma nova possibilidade de reconstrução das trajetórias 
singulares e da memória coletiva, resgatando fatos marcantes e construindo novas narrativas sobre os momentos de lutas do passado recente desse povo.

\section{CONSIDERAC̣ÕES FINAIS}

O processo de letramento dos alunos do terceiro ano do Ensino Médio da aldeia Barreiro Preto apresenta um conjunto de práticas que estão relacionadas a diferentes dimensões do cotidiano e ao intenso trabalho de (re)construção da identidade desses jovens. Por um lado, pôde-se verificar que os usos escolares da linguagem escrita estão em estreita sintonia com as demandas sociais e políticas da sociedade Xakriabá, possibilitando articulações com os movimentos sociais e com o trabalho político desenvolvido pelos indígenas em sua relação com o Estado. Por outro lado, os espaços que estão sendo conquistados por meio do uso de computadores ligados à internet se convertem em mais uma oportunidade de reafirmação da identidade étnica dos Xakriabá.

Além disso, a partir das demandas da comunidade e nas relações com os órgãos governamentais, as práticas de letramento têm possibilitado aos Xakriabá a negociação de novos postos de trabalho na reserva, como vagas nas áreas da saúde e da educação. De um modo dialético, a participação nesses postos coloca os sujeitos frente a novas demandas relacionadas a processos de leitura e escrita. Chamou-nos ainda a atenção o uso da escrita como forma de construção de narrativas em diários e memoriais, que são expressões do contínuo trabalho de reconstrução da identidade desses jovens.

Enfim, registramos a existência de sujeitos que, desvinculados de dimensões que demandam o uso da escrita, se voltam para a recuperação de usos escolares, percorrendo os mesmos textos, os mesmos livros, a fim de não perderem os vínculos com essa linguagem. Pudemos constatar que, assim como propõem os Novos Estudos para o Letramento (NLS, na sigla em inglês), as práticas de leitura e escrita dos alunos aqui estudados têm relação intrínseca com seu contexto social, estão vinculadas e são utilizadas em contextos específicos dos quais esses sujeitos fazem parte. Acredita-se que a entrada de vários alunos Xakriabá no curso de graduação indígena oferecido pela UFMG constitui uma grande conquista no campo do letramento acadêmico desses jovens, constituindo-se em mais um espaço importante de práticas a ser investigado. 


\section{REFERÊNCIAS}

BARTH, Fredrick. Grupos étnicos e suas fronteiras. In: POUTIGNAT, Philippe; STREIFFFENART, Jocelyne (Org.). Teorias da Etnicidade. Unesp, 1998.

BARTLET'T, Lesley; HOLLAND, Dorothy. Theorizing the space of literacy practices. 2002. Disponível em: <http://www.tc.columbia.edu/faculty/bartlett/publications / pdf/2_1WOK.pdf>. Acesso em: 8 jul. 2010.

BARTON, David. Literacy: an introduction to the ecology of written language. Blackwell: Oxford, 1994.

BARTON, David; HAMILTON, Mary. Local literacies: Reading and writing in one community. Routledge: London, 1998.

BAYNHAM, Mike. Literacies practices investigating: literacy in social contexts. Routledge: London, 1995.

BESNIER, Niko. Literacy and the notion of person on Nukulaelae Atoll. American Anthopologist, v. 93, n.3, 1991. Disponível em: < http://onlinelibrary.wiley.com/doi/10.1525/ aa.1991.93.3.02a00020/abstract>. Acesso em: 13 jun. 2013

BOURDIEU, Pierre. Esboço de uma teoria da prática. In: ORTIZ, Renato (Org.). Pierre Bourdieu: sociologia. São Paulo: Editora Ática, 1983.p. 46-82.

CARNEIRO DA CUNHA, Manuela Carneiro da. Cultura com aspas. 1. ed. São Paulo: Cosac Naify, 2009.

COPIMG - Conselho dos Povos Indígenas de Minas Gerais, 2009. Disponível em: <http:/ / www.sbrasil.org/copimg/index.php/nosso-povo.html>. Acesso em 13 de abr. de 2009.

DANTAS, Beatriz G., et al. Os povos indígenas no nordeste brasileiro: Um esboço histórico. In: CARNEIRO DA CUNHA, M (Org.). História dos Índios no Brasil. São Paulo: FAPES/ SMC/Companhia das Letras, 1992.p.431-452.

DIÁRIO DE CAMPO. Registros realizados durante observação em campo na Terra Indígena Xacriabá pelos autores, 2010.

DOLORES. Memorial elaborado em atividade escolar da escola Xukurank pela aluna, 2010.

Terra Indígena Xakriabá, 2011. 5 f. Digitado. Entrevista concedida aos autores.

EDER, Klaus. Identidades coletivas e mobilização de identidades. Revista Brasileira de Ciências Sociais, v. 18, n. 53, 2003. Disponível em: <http://www.scielo.br/pdf/rbcsoc/v18n53/18075. pdf $>$. Acesso em: 13 jun. 2013.

ELIANA. Terra Indígena Xakriabá, 2010. 5 f. Digitado. Entrevista concedida aos autores. Terra Indígena Xakriabá, 2010b. 6 f. Digitado. Entrevista concedida aos autores.

FUNAI - Fundação Nacional do Índio, 2010. Disponível em: <http://www.funai.gov.br/>. Acesso em 15 de nov. de 2010.

GALVÃO, Ana Maria de O. Oralidade, memória e narrativa: elementos para a construção de uma história da cultura escrita. In: GALVÃO, Ana Maria de O. (Org.). História da cultura escrita: Séculos XIX e XX. Belo Horizonte: Autêntica, 2007.

GEE, James P. Orality and literacy: From the savage mind to ways with words. In: Social Linguistics and literacy: ideology in discourses. London: Falmer Press, 1990.

GOODY, Jack. Literacy in traditional societies. New York: Cambridge University Press, 1968. . The domestication of the savage mind. New York: Cambridge University Press, 1977. 
GOODY, Jack; WATT, Ian. As consequências do letramento. São Paulo: Paulistana, 2006.

HEATH, Shirley B. What no bedtime Story Means: Narrative skills at home and school. Language in Society, n. 11, p. 49-76, 1982.

HYMES, Dell. Models of the interaction of language and social life. In: GUMPERZ; HYMES (Orgs.), Directions in sociolinguistics: The ethnography of communication. New York: Holt, Rhinehart \& Winston, 1972. p. 35-71.

JOÃO. Terra Indígena Xakriabá, 2010. 7 f. Digitado. Entrevista concedida aos autores.

Terra Indígena Xakriabá, 2011. 3 f. Digitado. Entrevista concedida aos autores.

KALMAN, Judith. Saber lo que es la letra. México: Siglo XXI, 2004.

OLIVEIRA, Roberto Cardoso. O trabalbo do antropólogo. São Paulo: UNESP; Paralelo 15, 1998.

PEREIRA, Verônica Mendes. A circulação da cultura na escola indígena Xakriabá. Tese (Doutorado) - Faculdade de Educação da Universidade Federal de Minas Gerais, Belo Horizonte, 2013.

SANTOS, Ana Flávia. Moreira. Da terra dos cablocos do Sr. São João à Terra indígena Xakriabá: as circunstâncias da formação do povo. 1997. Dissertação (Mestrado) -Universidade de Brasília, Brasília, 1997.

SCRIBNER, Sylvia; COLE, Michael. The psychology of literacy. Cambridge: Harvard University Press, 1981.

SÔNIA. Terra Indígena Xakriabá, 2010. 9 f. Digitado. Entrevista concedida aos autores.

STREET, Brian. Literacy in theory and practice. Cambridge: Cambridge University Press, 1984.

Social literacies: critical approaches to literacy in development, ethnography and education. London and New York: Longman, 1995.

What's "new" in New Literacy Studies? Critical approaches to literacy in theory and practice. Current issues in comparative education, v. 5, n. 2, 2003.

Perspectivas interculturais sobre o letramento. Revista Filologia linguística portuguesa, n. 8, p. 465- 488, 2007. Tradução Marcos Bagno. Disponível em: <http://www.fflch.usp.br/ $\mathrm{dlcv} /$ lport/flp/images/arquivos/FLP8/Street.pdf $>$. Acesso em 22 de jun. de 2013.

TASSINARI, Antonella Maria I. Escola Indígena: Novos Horizontes teóricos, novas fronteiras de educação. In: SILVA, A. L.; FERREIRA, M. K. L. (Org.). Antropologia, bistória e educação: a questão indígena e a escola. São Paulo: Global/ FAPESP, 2001.

\section{NOTAS}

1 Texto Apresentado no GT 10 - Alfabetização, Leitura e Escrita na 35a Reunião Anual da ANPED (Associação Nacional de Pós-Graduação em Educação)

${ }^{2}$ A pesquisa Lições de Escrita entre os Xakriabá iniciou-se em 2007, com edital do CNPq (Ciências Humanas), e teve continuidade com o Financiamento da FAPEMIG (Edital Universal, 2010/2012). Seus objetivos e seus pressupostos teóricos estão estreitamente articulados ao projeto "Letramento e cultura escrita", coordenado pela professora Marildes Marinho, tendo sido implementados paralelamente. A morte prematura de nossa colega de trabalho interrompeu de forma traumática esse processo de colaboração acadêmica. Suas contribuições teóricas e metodológicas, entretanto, foram essenciais para a produção deste artigo.

${ }^{3}$ Ver em: http://www.sbrasil.org/copimg/index.php/nosso-povo.html 
${ }^{4}$ Nome fictício, assim como todos os nomes de sujeitos entrevistados citados neste trabalho.

${ }^{\mathbf{5}}$ De acordo com dados fornecidos pela direção da escola Xukurank, a escola formou, em 2009, 20 alunos no Ensino Fundamental e oito no Ensino Médio; em 2010, 19 alunos no Ensino Fundamental e 13 no Ensino Médio.

${ }^{\mathbf{6}}$ Verônica Mendes Pereira (2013) investigou, em sua tese de doutorado - intitulada A circulação da cultura na escola indigena Xakriabä" (FAE/UFMG) - as diferentes formas de trabalho pedagógico construídas nas escolas indígenas Xakriabá com o objetivo de fazer circular e reinventar a cultura Xakriabá na escola por meio da instituição de um novo ator educacional denominado "Professor de Cultura". Esse novo ator é escolhido pela comunidade por ser um legítimo representante dos saberes tradicionais transmitidos de forma oral fora da escola. As aulas de cultura na escola são realizadas com base em concepções próprias de aprendizagem mediadas pela linguagem oral.

${ }^{7}$ Desde 2004, São João das Missões é administrada por um Xakriabá. Em 2012, um novo indígena foi eleito.

${ }^{8}$ A língua Akwê está sendo tomada de empréstimo dos Xerente para a recriação de uma "língua" Xakriabá, que paulatinamente começa a ser usada nas trocas entre os jovens e em momentos de rituais.

9 “Álbum seriado do AISAN - Agente Indígena de Saneamento. Etnia Xacriabá Aldeia Barreiro Preto". Foto tirada em 06/2011.

${ }^{10}$ Durante visitas, mesmo após longo período entre uma visita e outra, pudemos notar que alguns materiais se mantinham sob o plástico.

11 "Tudo posso naquele que me fortalece".

12 “Certificado de Conclusão - A Escola Estadual Indígena Xukurank, certifica que 'o aluno tal' concluiu o $3^{\circ}$ ano do Ensino Médio em 28 de dezembro de 2010, Aldeia Barreiro Preto - São João das Missões - MG".

Recebido: 07/11/2013

Aprovado: 28/08/2014

Contato:

Universidade Federal de São João Del-Rei

Departamento de Psicologia

Praça Dom Helvécio, 74 Dom Bosco

Sao Joao Del Rei|MG | Brasil

CEP 36.301-160 